\title{
La presencia cognitiva en ciencia de la información y su entorno
}

\author{
Radamés Linares C. \\ Universidad de la Habana. Facultad de Comunicación. \\ Departamento de Bibliotecologia y Ciencia de la Información. \\ E-mail: radames@fcom.uh.cu \\ rlinares@infomed.sld.cu
}

\section{Resumen}

Se analizan las circunstancias que enmarcaron la aparición y desarrollo de la perspectiva cognitiva en la ciencia de la información. Se argumenta el surgimiento de una nueva etapa de la historia de esta disciplina. Se examinan conceptos centrales de esta área de conocimiento desde este enfoque. Se hacen consideraciones en torno a las limitaciones de esta propuesta. Incluye bibliografía.

\section{Palabras-claves}

Ciencia de la Información; Historia; Perspectiva cognitiva

\section{The cognitive presence in information science and its environment}

\begin{abstract}
The circumstances that conditioned the appearance and development of the cognitive perspective in information science are analyzed. The emergence of a new stage of the history of this discipline is argued. Central concepts of this knowledge area are examined from this approach.

Considerations are presented around the limitations of this proposal. Bibliography included.
\end{abstract}

\section{Keywords}

Information science; History; Cognitive perspective.

\section{INTRODUCCIÓN}

Desde finales de los años 70, la presencia de la perspectiva cognitiva es una constante en casi todas las elaboraciones conceptuales y practicas del campo de conocimiento informacional, por lo que algunos afirman que goza de una ventaja hegemónica, navega entre casi todos los autores de la Ciencia de la Información. (Mostafa, 1999, 17)

Resulta de interés examinar no solo el conjunto de acontecimientos que hicieron visible la asimilación de esta nueva plataforma de comprensión del universo informativo, sino, también explorar las razones que en gran medida facilitan una explicación de este significativo cambio de orientación.

La Ciencia de la Información de los años originarios o fundacionales* congruente con su declarado carácter interdisciplinario incluye en los diversos autores que examinaron el tema, a la sicología como una de las disciplinas relacionadas con esta área de conocimiento. Este nexo se tradujo en asumir la orientación psicológica más afín a las concepciones que pautaron la creación del nuevo espacio en los terrenos teóricos y prácticos, por ello, el conductismo de fuerte vigencia en la psicología norteamericana de la primera mitad del siglo $\mathrm{XX}$, con su peculiar rechazo de los procesos mentales y su creencia solo en la conducta observable, es asumido explícitamente o no.

A su vez, los fundadores de esta disciplina, al calificarla como "ciencia", no solo utilizaron este término por su elevado prestigio social y su indiscutible influencia en el imaginario intelectual de esos años, sino que también suscribieron el modelo de racionalidad científica postulado entre los siglos XVI y XIX, y en consecuencia propugnaron una Ciencia de la Información que pretendía ser similar a las ciencias empíricas y naturales, con las consiguientes aspiraciones de cientificidad, alcanzables a través de la "objetividad" y "mensurabilidad" propias de esas disciplinas.

El conductismo como tendencia psicológica tenia similares aspiraciones, era de esperar entonces, que esta perspectiva fuera asumida por los padres fundadores de esta

\footnotetext{
* La etapa fundacional se enmarca entre los años 1945 y 1978.
} 
área de conocimiento; es por lo cual aquellos tópicos del universo de esta materia que involucraban personas o grupos de estas, eran examinados desde este enfoque, una buena muestra son los estudios de usuarios realizados en esta época (Wiegand, 1999, 17).

Estas perspectivas van a pautar el proceso de construcción de esta disciplina en sus primeros años en esta y otras dimensiones de este campo.

\section{Ciencia en formación}

Las últimas décadas del siglo XX constituyen para la Ciencia de la Información una fase de ruptura y diferenciación como expresión de la evolución de una ciencia en formación, enmarcada en circunstancias económicas, científicas, tecnológicas e informacionales raigalmente distintas a la etapa precedente.

Del conjunto de transformaciones de esta fase es de interés lo acontecido en ciertas dimensiones del entorno académico e intelectual, sin que esto reduzca la importancia de los profundos cambios que se producen en las practicas económicas de los países altamente desarrollados, al surgir el discurso neoliberal o la decisiva relevancia de las invenciones e innovaciones en las tecnologías computacionales y su penetrante impacto en la vida económica y social.

La atmósfera intelectual de los países desarrollados a fines de siglo gravita en la situación informacional y en su comunidad profesional, especialmente con las reflexiones sobre la ciencia o el conocimiento científico, variante del conocimiento institucionalizado de axiomática hegemonía.

La vigencia del modelo naturalista, cientificista y positivista en el terreno del conocimiento declina a lo largo del siglo XX. Esta crisis abarca el sistema global de los conocimientos y de las ciencias, y particularmente las Ciencias Sociales reproducen, desde su realidad, las turbulencias que afectan la totalidad del saber.

Las Ciencias Sociales, desde el siglo XIX hasta el período que se estudia, buscan constantemente su afirmación como conocimiento científico. Primero estudia la sociedad desde los principios epistemológicos y metodológicos acordes con las concepciones dominantes desde el siglo XVI, asumiendo los fenómenos sociales como "cosas", restringidas a sus dimensiones externas, observables, objetivas y mensurables. Luego reivindica una perspectiva epistemológica y metodológica específica, propia para el ser humano y alternativa al modelo naturalista y positivista.
Estas tendencias resumen los paradigmas en las Ciencias Sociales que nosotros preferimos denominarlos, respectivamente, como paradigma explicativo y paradigma interpretativo, nombres que toman en cuenta el largo debate en el proceso de construcción de las Ciencias Sociales sobre el objetivo final dado a tales ciencias, que para unos es el de explicar y para otros el de interpretar o comprender los objetos sociales estudiados por el investigador (Briones, 1996, 87).

\section{Concepciones}

En rigor, es a partir de los años 60 que se inicia y desarrolla una lectura desde las Ciencias Sociales que subraya la necesidad de estas disciplinas de entroncarse con lo específicamente humano, por ello, se desarrollan concepciones que rescatan el papel de la subjetividad humana en la comprensión de la problemática social; es de notar, que serán los años 80 el momento en que estas posturas alcanzan una indiscutible visibilidad en varias disciplinas sociales: Comunicación, Lingüística, Psicología, etc, son los tiempos del "retorno al receptor", de la "vuelta al lector".

Esta especie de "énfasis en el sujeto o la subjetividad" va a tener su manifestación en la Ciencia de la Información del final del siglo XX a través de la presencia de la perspectiva cognitiva.

La sicología cognitiva, que tuvo su inicio en un Simposio sobre Teoria de la Información, realizado en el Massachussets Institute of Technology (MIT) en septiembre de 1956, donde científicos importantes en el desarrollo del nuevo pensamiento presentaron artículos inéditos: Herbert Simon, Noam Chomsky y Claude Shannon (Barreto, 2002, 9), es el reemplazo del conductismo dominante y la defensa de los aspectos subjetivos y significativos de la experiencia psicológica, al tratar de explicar lo que pasa en el mundo interior.

Esta superación privilegia el estudio de procesos mentales como la percepción, atención, memoria, lenguaje, razonamiento y representaciones para comprender cómo se desarrollan estos procesos en los seres humanos.

Una de las primeras manifestaciones de cambios al interior de la Ciencia de la Información, desde los finales de los años 70, se produce en la noción reconocida como objeto de esta disciplina - la información -, que comienza a ser concebida desde el nuevo enfoque.

El iniciador del enfoque cognitivo en Ciencia de la Información es Bertran C. Brookes. En su interés por construir los fundamentos para esta disciplina, en fecha tan temprana como 1974, propone la ecuación fundamental de la Ciencia de la Información, que también puede llamarse 
ecuación cognitiva de la Ciencia de la Información, de la que puede extraerse su concepción de información y que se expresa de esta forma:

$K(S)+D(I)=K(S+D S)$

Donde K (S) es una estructura de conocimiento, K (S+ DS) es la estructura de conocimiento modificada y D (I) es quien modifica esa estructura (Mostafa, 1999). En otros términos, "eso" que altera o modifica el conocimiento, es la información.

Otra de las lecturas novedosas de la noción de información, desde esta perspectiva, la propone Nicholas Belkin, quien no se limita a introducir su concepto, sino que se adentra en un aspecto medular, las posibilidades o requisitos de un concepto de información para la Ciencia de la Información.

Este aspecto es uno de los mayores aportes, recordándose que el debate de los años fundacionales intenta delimitar o encontrar razones universales sobre la noción información y que faltan propuestas concretas que se centren en ella.

El propio Belkin, en 1978, resume de esta forma sus condiciones (Belkin, 1978, 16,17):

\section{REQUISITOS DE UN CONCEPTO DE INFORMACIÓN PARA LA CIENCIA DE INFORMACIÓN}

1. Debe referirse a la información dentro del contexto de la comunicación con un propósito y una intención determinada.

2. Debe explicar la información como un proceso de comunicación social entre seres humanos.

3. Debe explicar lo demandado o deseado de la información.

4. Debe explicar el efecto de la información sobre el receptor.

5. Debe explicar la relación entre la información y el estado de conocimiento del generador y del receptor.

6. Debe explicar los diversos efectos de los mensajes presentados de diferentes modos.

7. Debe ser generalizable más allá del caso individual.

8. Debe brindar un medio para la predicción del efecto de la información.

Este sistema de ideas excede meros "requisitos" y resalta sus concepciones de la información y de la disciplina que la estudia, pues inserta a la información en el ámbito de los procesos de comunicación social y recalca que el problema fundamental de la Ciencia de la Información es la información deseada y su efecto sobre el usuario. Notablemente incorpora, en forma integrada, los conceptos comunicación y conocimiento, que desde el prisma de lo cognitivo se vuelven imprescindibles en la comprensión del fenómeno de la información.

Los criterios de Brookes, continuados por Belkin, que distinguen al enfoque cognitivo, evidencian un cambio, se coloca al sujeto del otro lado de la barrera, como factor determinante en la definición del concepto información.

Una gran parte de los estudios de los cognitivistas está dedicada a los estudios de usuarios (Mostafa, 1999, 21). Los estudios de usuarios en la etapa fundacional describen las acciones de los usuarios y expresan sus necesidades desde los sistemas de información. En los finales de los años 70 , al igual que en otras esferas, se produce un rechazo de esas posiciones, y surgen nuevas reflexiones sobre la problemática del usuario.

\section{Enfoque cognitivo}

El enfoque cognitivo comienza puntualizando el desconocimiento por parte de las visones anteriores del enorme significado del mundo interior del individuo en los procesos de asimilación y uso de la información (Ferreira, 1995).

Uno de los mejores exponentes del enfoque cognitivo en los estudios de usuarios es el sense-making, introducido por la norteamericana Brenda Dervin. ${ }^{*}$ Es una propuesta teórica y metodológica que propone una separación radical entre el ser humano y los sistemas de información. Esta distinción entre mente y mundo es propia de la perspectiva cognitivista.

El sense-making entiende a la información como un dato incompleto al cual el individuo atribuye sentido a partir de la intervención de sus esquemas interiores. Coloca al usuario en la cima de su interés, aboga porque el comportamiento de la búsqueda y uso de información esté modelado por el universo cognitivo del usuario, rechaza el uso exclusivo de las variables sociodemográficas y dicta que el sistema de información se subordine a los intereses del usuario (Dervin, 1983).

Desde mediados de los años 90, la hegemonía cognitiva es abiertamente cuestionada, Birger Hjørland es uno de los más lúcidos críticos del enfoque cognitivo. Se

\footnotetext{
* Profesora de la School of Journalism \& Communication. The Ohio State University.
} 


\section{Radamés Linares C.}

cuestiona la marcada exclusión en lo cognitivo de los entornos sociales y culturales en que participa el individuo, por lo que declara incorporar en la investigación psicológica una perspectiva social, cultural e histórica más amplia (Hjørland, 1995).

Aventura una opción al mentalismo y la subjetividad de los investigadores cognitivos y reorienta la unidad de estudio: del nivel individual a las comunidades humanas, sean estas sociales, disciplinarias o del conocimiento. Con esta posición se adhiere al enfoque sociocognitivo (Hjørland, 1995).

La tendencia sociocognitiva no es apenas la crítica al cognitivismo ortodoxo, sino una nueva manera de asumir la visión cognitiva, integrando este enfoque al universo sociológico y cultural, desplazando la atención de la estructura individual del conocimiento a los "dominios del discurso" para las comunidades que producen, intercambian y consumen conocimiento (Hjørland, 1995, 51).

El análisis de dominio que presenta Hjørland conforma una lectura de los fenómenos informacionales que supera el dogmatismo del enfoque cognitivo. El dominio del discurso o del conocimiento es un espacio científico o profesional con estructuras únicas de comunicación, tipos únicos de documentos y combinaciones informacionales específicas. Para identificar el dominio del discurso y la comunidad disciplinaria o profesional de conocimiento, privilegia el contexto que lo produce (Hjørland, 1995).

La presencia cognitiva en Ciencia de la Información no se reduce ni a los autores y posiciones expuestos, su carácter paradigmático durante una etapa de la historia de esta disciplina envuelve obviamente otras dimensiones de las construcciones conceptuales y practicas de este espacio de conocimiento. Aquí, solo hemos apuntado algunos aspectos de un proceso mucho más amplio.

En síntesis:

1. La historia de la Ciencia de la Información de las ultimas décadas del siglo XX se inscribe en el contexto de una situación económica, política, social, científica, informacional y tecnológica, marcada por el cambio y las transformaciones.

2. Las Ciencias Sociales de los finales del siglo XX debaten sus fundamentos epistemológicos $y$ metodológicos entre dos paradigmas: el explicativo, de raíces positivistas y cientificistas, y el interpretativo, que propugna un discurso propio del espacio humano y social.
3. La Sicología, uno de los espacios de conocimiento más influyente en el campo de la Ciencia de la Información, desarrolla desde los años 60 de ese siglo, una nueva perspectiva, el enfoque cognitivo, cuya idea del rescate del mundo interior del sujeto es de significativa importancia en el universo informacional.

4. El entorno intelectual de finales del siglo XX se distingue por un cuestionamiento de los modelos cientificistas y naturalistas vigentes, vislumbrándose en todos los espacios intelectuales un resurgimiento de la subjetividad humana.

5. La Ciencia de la Información en las últimas décadas del siglo XX descubre su pertenencia al universo de las Ciencias Sociales y se incorpora al debate en torno al rechazo del modelo positivista.

6. El enfoque cognitivo, desde finales de los años 70 del siglo XX, se convierte en la plataforma teórica por excelencia, desde la cual se conforma la armazón conceptual de la Ciencia de la Información de ese momento.

7. La crítica del sociocognitivismo al enfoque cognitivo ortodoxo, introduce la necesidad de apostar por las determinaciones sociales y culturales en cualquier propuesta conceptual en el terreno informacional.

Artigo recebido em 03-12-2003 e aceito para publicação em 24-04-2004. 


\section{La presencia cognitiva en ciencia de la información y su entorno}

\section{REFERENCIAS}

BARReto, A. de A. A condição da informacao. Revista São Paulo em Perspectiva, v. 16, n. 3, p. 67-74, 2002.

BELKIN, N. Information science and the phenomena of information. Journal of the American Society for Information Science, v. 27, p. 197-204, 1978.

BERNAL, J. Historia social de la ciencia. La Habana : Ciencias Sociales, 1986. 498 p. t. 2

BORKO, H. Information science: what is it? American Documentation, v. 19, n. 1, p. 3-5, 1968.

BRIONES, G. Epistemología de las ciencias sociales. Bogotá : ICFES, 1996. $233 \mathrm{p}$.

BROOKES, B. C. The foundations of Information science. Information science: the changing paradigm. Journal of Information Science, v.3, p. 3 12, 1995. pt. IV.

The foundations of Information science: philosophical aspects. Journal of Information Science, v. 2, p. 125-133, 1980. pt. I

DERVIN, B.; M. Nilan. Information needs and uses. Annual Review of Information Science and Technology, v. 21, p. 3-33, 1986.

FERREIRA, S. M. Soares Pinto. Novos paradigmas e novos usuários de informação Ciência da Informação, Brasília, v. 25, n. 2, 1995.

HJØRLAND, B. Epistemology and the socio-cognitive: perspective in information science. Journal of the American Society for Information Science and Technology v. 53, n. 4, p. 257-270, 2002.

Toward a new horizon in information science: domain analysis. Journal of the American Society for Information Science, v. 46, n. 6, p. $400-425,1995$
Library and Information science: practice, theory and philosophical basis. Information Processing and Managment., London, v. 36, p. 501-530, 2000.

HOBSWABM, E. Historia del siglo XX. Argentina : Grijalbo Mondadorim, 1998. 597 p. 2.

INGWEERSEN, P. Information retrieval interaction. Disponivel em: <http://www.db.dk/pi/ir>.

JACOB, E. K.; D. Shaw Sociocognitive perspectives on representation. Annual Review of Information Science and Technology , v. 33, p. 131-185, 1998.

MOSTAFA, S. Referenciais teóricos da área da informação. Transinformação, Campinas, SP, v. 11, n. 1, p. 16-26, jan. 1999.

SARACEVIC, T. Information science. Journal of the American Society for Information Science E Technology, v. 50, n. 12, p. 1051-1063, 2000.

Information science: origin, evolution and relations. In: INTERNATIONAL CONFERENCE ON CONCEPTIONS OF LIBRARY AND INFORMATION SCIENCE. 1992. Tampere, Finland. Historical, empirical and theoretical perspectives. Proceedings... [S. 1. : s. n. 1992?].

Interdisciplinary nature of Information science. Ciência da Informação, Brasília, v. 24, n. 1, 1995.

WIEGAND, W. A. Tunnel vison and blind spots: what the past tells us about the present reflections on the twenteith century history of American librarianship. Library Quarterly, v. 69, n. 1, p. 1-17, 1999. 